Tropical Journal of Pharmaceutical Research January 2021; 20 (1): 121-128

ISSN: $1596-5996$ (print); 1596-9827 (electronic)

(C) Pharmacotherapy Group, Faculty of Pharmacy, University of Benin, Benin City, 300001 Nigeria.

\title{
Sericea lespedeza (Lespedeza cuneata) whole plant extract enhances rat muscle mass and sperm production by increasing the activity of NO-cGMP pathway and serum testosterone
}

\author{
SangJoon $\mathrm{Mo}^{1,3}$, Eun Young $\mathrm{Kim}^{2}$, Sun-Hyang $\mathrm{Choi}^{3}$, Sanghyun Lee ${ }^{4}$, Seong \\ Lee $^{5}$, Jin Chul Ahn ${ }^{1,3 *}$ \\ ${ }^{1}$ Medical Laser Research Center, Dankook University, ${ }^{2}$ Beckman Laser Institute Korea, ${ }^{3}$ Center for Bio-Medical Engineering \\ Core Facility, Dankook University, ${ }^{4}$ Department of Integrative Plant Science, Chung-Ang University, Anseong 17546, ${ }^{5}$ Research \\ Institute of Clinical Medicine, Dankook University Hospital, Cheonan 31116, Korea
}

*For correspondence: Email: jcahn@dankook.ac.kr; Tel: +82-41-550-3899

\begin{abstract}
Purpose: To analyze the effects of an aqueous extract of Sericea lespedeza (SL) on rat male menopause.

Methods: Levels of nitric oxide (NO), endothelial nitric oxide synthase (NOS), cGMP, and prostaglandin E2 (PGE2) in the penile corpus cavernosum of the rats were evaluated using appropriate kits. Serum levels of dihydrotestosterone (DHT), testosterone, sex hormone-binding globulin (SHBG), and 17-beta hydroxysteroid dehydrogenases (17 $\beta-H S D)$ were measured with enzyme-linked immunosorbent assay kits. Total and motile sperms were counted on a hemocytometer. Histological changes in rat testis and epididymis were analyzed with hematoxylin and eosin staining.

Results: The levels of NO, NOS, and cGMP (but not PGE2) increased in a dose-dependent manner ( $p$ $<0.05)$ upon administration of an aqueous extract of SL (AESL), while levels of DHT, 17 $\beta-H S D$, and testosterone increased in the group administered with $300 \mathrm{mg} / \mathrm{kg}$ of AESL. Epididymal sperm count increased by $24 \%$ in such rats compared to controls $(p<0.05)$.

Conclusion: The aqueous extract of SL improves sperm count and muscle mass in rats by increasing the levels of NO, NOS, cGMP and testosterone. Thus, SL extract can potentially be developed as an alternative therapeutic agent for clinical management of TDS.
\end{abstract}

Keywords: NO-cGMP, Testosterone, Hormones, Sperm count, Muscle mass, Sericea lespedeza, Lespedeza cuneata

This is an Open Access article that uses a fund-ing model which does not charge readers or their institutions for access and distributed under the terms of the Creative Commons Attribution License (http://creativecommons.org/licenses/by/4.0) and the Budapest Open Access Initiative (http://www.budapestopenaccessinitiative.org/read), which permit unrestricted use, distribution, and reproduction in any medium, provided the original work is properly credited.

Tropical Journal of Pharmaceutical Research is indexed by Science Citation Index (SciSearch), Scopus, International Pharmaceutical Abstract, Chemical Abstracts, Embase, Index Copernicus, EBSCO, African Index Medicus, JournalSeek, Journal Citation Reports/Science Edition, Directory of Open Access Journals (DOAJ), African Journal Online, Bioline International, Open-J-Gate and Pharmacy Abstracts

\section{INTRODUCTION}

Hormones are generally classified as either anabolic or catabolic based on their effects within the organism. The sex hormones are anabolic, like growth hormone, insulin-like growth factor, insulin, dehydroepiandrosterone, and thyroid hormone. Although individual differences exist, levels of most anabolic hormones begin to fall after age 30 in humans [1], perhaps as a result of 
aging. The average annual decline in total testosterone is $1-2 \%$ in males age 39 to 70 years; the decline in free testosterone is more rapid because the level of sex hormone-binding globulin (SHBG) increases with age $[2,3]$. Decline in testosterone affects sexual instability and lethargy, muscle mass, sexual maturity, bone density, liver function, hematopoietic function, and immune function [2,4,5]. In particular, low testosterone triggers changes in the endocrine system, similar to female menopause, resulting in male hormone deficiency, as well as a decrease in the penis' ability to induce and maintain an erection [2,6-8].

Nitric oxide (NO) which mediates penile cavernous smooth muscle relaxation, is a representative endothelium-derived relaxant synthesized from L-arginine by endothelial nitric oxide synthase (eNOS) in endothelial of corpus cavernosum $[9,10]$. NO activates the guanylate cyclase of penile cavernous smooth muscle cells; that enzyme converts guanosine triphosphate to cGMP. When NO generated in endothelial cells increases cGMP in smooth muscle cells, protein kinase $G$ is activated, the inflow of extracellular $\mathrm{Ca}^{2+}$ is blocked, and smooth muscle cell relaxation triggers an erection [11,12]. Testosterone deficiency syndrome is the principal symptom of male menopause. Male hormones are of great academic interest and the subject of debate worldwide. Recent research has confirmed that testosterone supplementation for males exhibiting hypogonadism affords various benefits. However, although hormone replacement therapy is useful, their long-term effects, stability, and capacity to delay aging remain controversial [13-16]. Therefore, the use of herb-derived hormone substitutes to relieve menopausal symptoms might be safer. Sericea lespedeza (SL; or Lespedeza cuneata) is a dicotyledonous plant of the Fabaceae found in Korea, Japan, Taiwan, and India. It has long been used to treat cough and asthma, low vitality, and premature ejaculation. In particular, $L$. cuneata has been shown to enhance vasodilation, the activity of dihydrotestosterone (DHT) and 17- $\beta$-hydroxysteroid dehydrogenases (17 $\beta-H S D)$, testosterone production [17-20]. This study has been planned to evaluate the effects of AESL on rat blood testosterone, muscle mass, and sperm count.

\section{EXPERIMENTAL}

\section{Preparation of an aqueous extract of SL (AESL)}

Sericea lespedeza was harvested from a suburban field in Boeun, Chungbuk, Republic of
Korea in November 2017, and authenticated by Dr. Sanghyun Lee (Professor of Botany at the Department of Integrative Plant Science, ChungAng University, Ansung, Korea). The dried SL $(1,000 \mathrm{~g})$ was extracted with $10 \mathrm{~L}$ boiled distilled water at $100{ }^{\circ} \mathrm{C}$ for $2 \mathrm{~h}$. The aqueous extract was harvested by centrifugation at $2,500 \times \mathrm{g}$ for 20 min at $4{ }^{\circ} \mathrm{C}$ and filtered through Whatman No. 1 filter paper (GE Healthcare, Pittsburgh, PA, USA). The supernatant was lyophilized to a powder $(127.5 \mathrm{~g})$ that was stored at $-20{ }^{\circ} \mathrm{C}$ before use. The AESL was dissolved in normal saline (JW Pharmaceutical, Dangjin, Korea) before being administered to rats.

\section{Animals}

Sprague-Dawley (SD) rats (sixteen-weeks old, male) were purchased from Orient Bio Inc. (Seongnam, Korea) and housed under conditions controlled at $22 \pm 2{ }^{\circ} \mathrm{C}$ and $55 \pm 5 \%$ humidity. The rats had ad libitum access to a standard laboratory diet and water. All conditions of animal care and experimentation were carried out compliance with the Guide for Care and Use of Laboratory Animals of the National Institutes of Health, and the EEC directive of 1986 (86/609/EEC) [21,22]. This study was approved by the Animal Institutional Care and Utilization Committee of Dankook University (approval no. DKU-18-012). Thirty rats were randomly divided into three groups of 10 each: control (saline orally), low-dose AESL (150 mg/kg/day AESL orally for 4 weeks), and high-dose AESL (300 $\mathrm{mg} / \mathrm{kg} /$ day $\mathrm{AESL}$ orally for 4 weeks). The rats were weighed every week. All rats were anesthetized via intramuscular injection of Zoletil (30 mg/kg; Virbac Laboratories, Carros, France) and Rompun (10 mg/kg; Bayer Korea, Seoul, Korea) 4 weeks later and sacrificed. Blood samples were collected from the abdominal aortae into serum-separating tubes and centrifuged at $3,000 \times g$ for $15 \mathrm{~min}$ at $4{ }^{\circ} \mathrm{C}$. Sera were stored at $-80{ }^{\circ} \mathrm{C}$ prior to analyses. The quadriceps muscle, kidney, testis, and epididymis were removed and weighed. Testis and epididymis were used after fixing by immersing in Bouin's solution. On the day of sacrifice, a portion of the penile corpus cavernosum was placed in $0.1 \mathrm{M}$ potassium phosphate buffer ( $\mathrm{pH} 7.4)$, homogenized with an Ultra Turnax T25 (IKA-Lab, Staufen, Germany), and centrifuged at $516 \times g$ at $4{ }^{\circ} \mathrm{C}$. Each supernatant was analyzed to assess the activity of vasodilation.

\section{Measurement of NO in vitro}

Human umbilical vein endothelial cells (HUVECs) were purchased from Lonza (Walkersville, MD, 
USA) and the cultured in the medium of an EGM2 endothelial cell kit (Lonza) in a humidified atmosphere under $5 \%(\mathrm{v} / \mathrm{v}) \mathrm{CO}_{2}$ at $37^{\circ} \mathrm{C}$. The medium was replaced once every two days. All in vitro experiments were performed with HUVECs at passage numbers less than 10 . Penicillin (100 units $/ \mathrm{mL})$ and streptomycin $(100 \mu \mathrm{g} / \mathrm{mL})$ were added to all media. HUVECs were seeded at $1 \times$ $10^{6}$ cells/well into six-well plates, and the medium changed every 24 h. Cells were incubated for $24 \mathrm{~h}$ with various concentrations of $\mathrm{AESL}$, and then the supernatants were mixed with the equal volumes of Greiss solution (Sigma, St. Louis, MO, USA) prior to the measurement of absorbance at $450 \mathrm{~nm}$ in a microplate reader (BioTek, Winooski, VT, USA). The NO concentrations were determined from the appropriate standard curve derived with nitrite standard.

\section{Measurement of NO, NOS NOS, cGMP and PGE2 in vivo}

Levels of NO, NOS, cGMP, and PGE2 in the penile corpus cavernosum were analyzed to assess vasodilator function. The NO levels of the homogenized cavernous supernatant were analyzed using a colorimetric Nitrite/Nitrate assay kit according to the manufacturer's protocol (Sigma). To analyze NOS levels, homogenized cavernosum supernatants were treated with $1 \mu \mathrm{M}$ ionomycin and then incubated for $2 \mathrm{~h}$. The supernatant was then collected by centrifugation at $516 \times \mathrm{g}$, transferred to a new tube, and analyzed with a neuronal NOS kit (R\&D Systems, Minneapolis, MN, USA) according to the manufacturer's protocol.

For analysis of cGMP levels, a sample was made by adding 1:4 ethanol to the homogenized cavernosum and centrifuging at $516 \times \mathrm{g}$ for 10 min to remove non-specific proteins. The supernatant which the non-specific protein was removed was dried under reduced pressure, dissolved with the equal volume of PBS, and estimated using a cGMP EIA kit (Cayman, Ahn Arbor, MI, USA) according to the manufacturer's protocol. For the estimate of PGE2, PGE2 levels were determined by PGE2 EIA kits (Cayman Chemicals, Ann Arbor, MI) after centrifuging the homogenized cavernosum.

\section{Measurement of serum DHT, testosterone, SHBG, and $17 \beta-H S D$}

The levels of DHT, testosterone, SHBG, and $17 \beta-H S D$ were measured to assess sexual functioning. Blood was centrifuged and diluted in the various assay buffers. The levels of DHT, testosterone, and $17 \beta-H S D$ were measured with an ELISA kit (Mybioscience), and SHBG was assayed with an SHBG ELISA kit (Cusabio, Temecula, CA, USA). All assays followed the manufacturers' protocols.

\section{Measurement of quadriceps muscle mass}

Both hindlimb muscles were removed and weighed. A vernier caliper was used to determine muscle thickness. The quadriceps were separated and weighed.

\section{Sperm count and histopathological changes}

Each epididymis was removed, minced and incubated in M199 medium with $0.5 \%$ (w/v) BSA at $37{ }^{\circ} \mathrm{C}$ for $10 \mathrm{~min}$. For sperm counting, $100 \mu \mathrm{L}$ of the sperm suspension was diluted with M199 medium. Approximately $10 \mu \mathrm{L}$ from the diluted sperm solution was transferred into a haemocytometer and then counted. To analyze the percentage of sperm mobility, the diluted suspension was prepared by re-pipetting. A small volume $(10 \mu \mathrm{L})$ was placed on a prewarmed haemocytometer at $37{ }^{\circ} \mathrm{C}$ and then sperm mobility was counted and assessed. To investigate morphological changes in the testis and epididymis, the tissue was dehydrated using a graded series of ethanol baths, cleared by xylene, and then impregnated with paraffin wax. Sections (5 $\mu \mathrm{m}$ in thickness) were stained with Harris's hematoxylin and eosin, and then observed under a microscope (Olympus, Tokyo, Japan).

\section{Statistical analysis}

Statistical analysis was performed on the data with Prism for Windows (version 7.0; GraphPad Software, San Diego, CA, USA). Data are presented as mean \pm standard deviation (SD). The significance of the statistical values was investigated via a one-way analysis of variance (ANOVA) followed by post hoc Tukey HDS test. $p<0.05$ was taken to indicate significance.

\section{RESULTS}

\section{NO production by HUVECs}

Various concentrations of AESL were added to HUVEC cells and then NO levels were measured $24 \mathrm{~h}$ later. As shown in Figure 1, NO levels significantly increased dose-dependent manner of AESL in HUVEC cells compared to control values $(16.58 \pm 0.77 \mathrm{mM})$. In particular, the NO levels of HUVEC cells treated with 100, 200 and $500 \mathrm{mg} / \mathrm{ml}$ of AESL were significantly increased by 21,26 and $34 \%$, respectively, compared to the control group. 


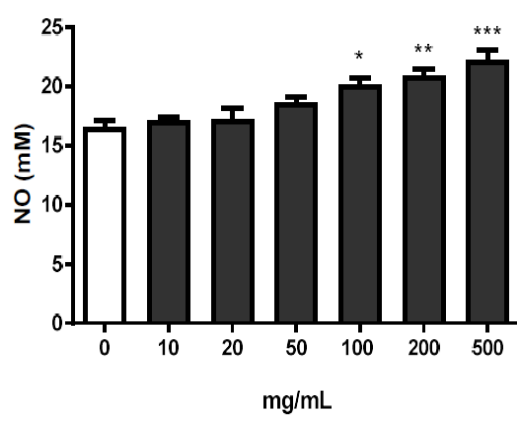

Figure 1: Effect of AESL on NO in HUVECs in vitro. AESL at various concentrations was added to HUVECs and NO measured 24 h later; $p<0.05,{ }^{* *} p<$ 0.01 , and ${ }^{* * *} p<0.001$ compared to control

\section{NO content of penile corpus cavernosum}

Since the levels of NO, NOS, cGMP and PGE2 are important neurotransmitters in the penile corpus cavernosum, the effect of AESL on their levels has been analyzed. As shown in Figure $2 \mathrm{~A}$, the level of NO in AESL 150 and $300 \mathrm{mg} / \mathrm{kg}$ administered group increased in 16 and $51 \%$, respectively, when compared to the control (5.36 $\pm 0.95 \mathrm{mM}$ ). The statistically significant increase in NO levels was in the administered group with $300 \mathrm{mg} / \mathrm{kg}$ of AESL. The levels of NOS in AESL 150 and $300 \mathrm{mg} / \mathrm{kg}$ administered groups increased in 23 and $50 \%$, respectively, compared to the control group $(9.32 \pm 1.52 \mathrm{U} / \mathrm{L})$. In particular, there has been a significant increase in the AESL $300 \mathrm{mg} / \mathrm{kg}$ administered group (Figure 2B). In the case of cGMP levels, the AESL 150 and $300 \mathrm{mg} / \mathrm{kg}$ administered groups increased in 11 and $36 \%$, respectively, compared to the control group (0.052 \pm 0.007 $n M)$. This level also showed significantly increase in the AESL $300 \mathrm{mg} / \mathrm{kg}$ administered group (Figure 2C). However, there was no increase in the level of PGE2 in all AESL administered groups (Figure 2D).

\section{Blood male hormones}

Figure $3 \mathrm{~A}$ shows that blood levels of DHT increased by 12 and $25 \%$ in rats treated with AESL at doses of 150 and $300 \mathrm{mg} / \mathrm{kg} / \mathrm{day}$, to $608.3 \pm 35.9$ and $683.9 \pm 63.2 \mathrm{pg} / \mathrm{mL}$ (control: $545.2 \pm 44.7 \mathrm{pg} / \mathrm{mL}$ ), respectively. Testosterone levels increased by 7 and $20 \%$ to $1,526.69 \pm$ 83.37 and $1,716.66 \pm 83.17 \mathrm{pg} / \mathrm{mL}$ (control: $1,430.06 \pm 110.59 \mathrm{pg} / \mathrm{mL}$ ), respectively (Figure $3 \mathrm{~B}$ ). Levels of $17 \beta$-HSD increased by 33 and 65 $\%$ to $0.963 \pm 0.157$ and $1.197 \pm 0.102 \mathrm{pg} / \mathrm{mL}$ (control: $0.723 \pm 0.076 \mathrm{pg} / \mathrm{mL}$ ), respectively (Figure 3C). Sex hormone-binding globulin levels decreased by 4.3 and $16.7 \%$ to $0.441 \pm 0.091$ and $0.384 \pm 0.086 \mathrm{ng} / \mathrm{mL}$ (control: $0.461 \pm 0.046$ $\mathrm{ng} / \mathrm{mL}$ ), respectively (Figure 3D). Overall, the AESL $300 \mathrm{mg} / \mathrm{kg}$ administered group had significant increases in DHT, testosterone, and $17 \beta$-HSD levels, while the levels of SHBG decreased.
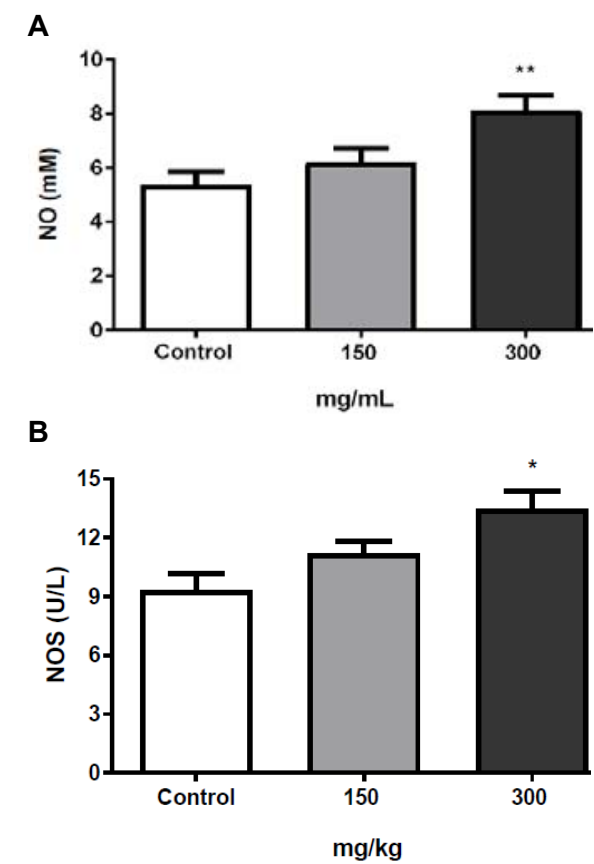

C

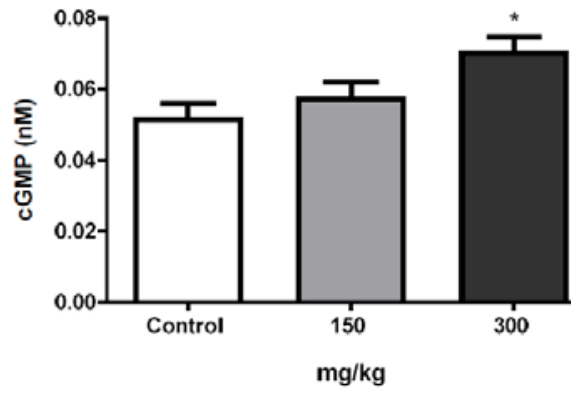

D

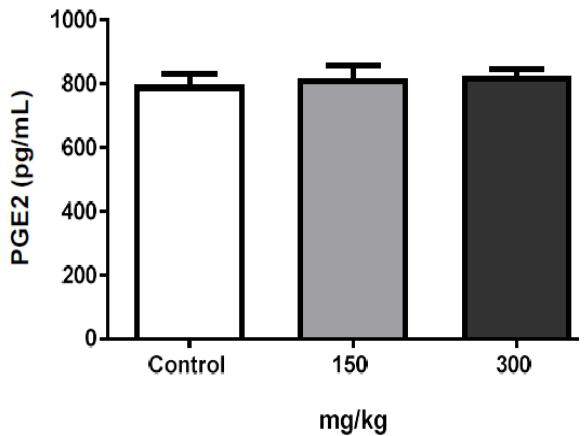

Figure 2: Effect of AESL on NO, NOS, cGMP, and PGE2 in the supernatants of homogenized penile corpus cavernosum. (A) NO. (B) NOS after treatment with $1 \mu \mathrm{M}$ ionomycin for $2 \mathrm{~h}$. (C) cGMP. (D) PGE2; " $p$ $<0.05, " * p<0.01$, compared to control

Trop J Pharm Res, January 2021; 20(1): 124 
A

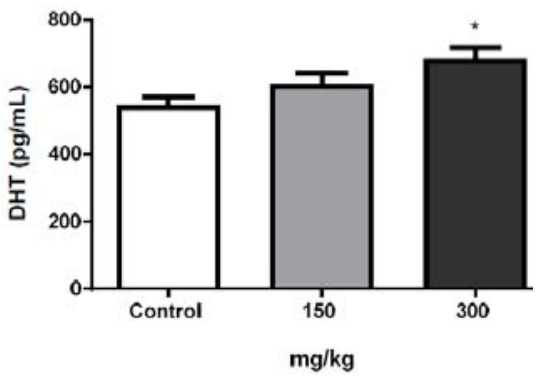

B

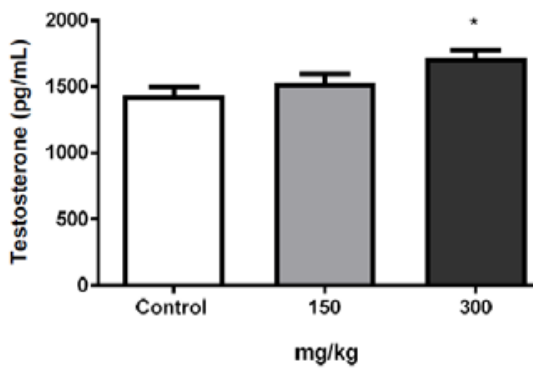

C

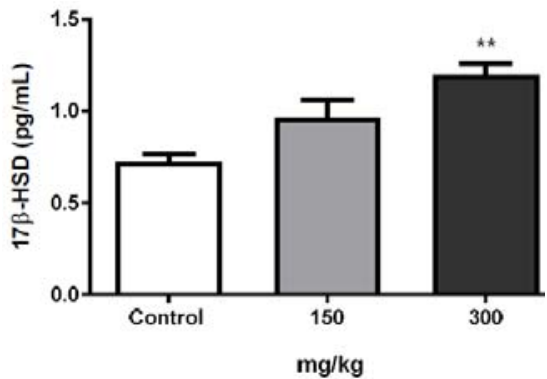

D

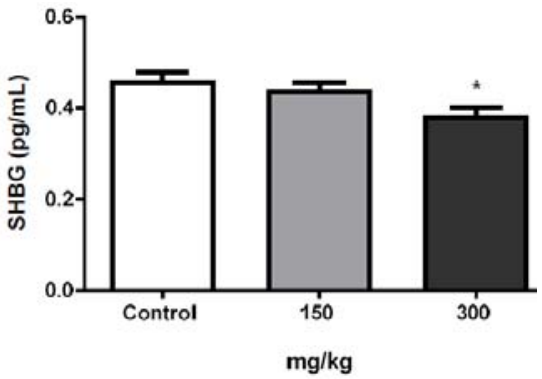

Figure 3: Effects of AESL on serum levels of DHT, testosterone, SHBG, and 17ß-HSD. Sera were diluted three-fold with the various assay buffers. Concentrations of (A) DHT, (B) testosterone, (C) 17 $\beta$ HSD, and (D) SHBG. $p<0.05,{ }^{* *} p<0.01$, compared to control

\section{Effect of AESL on muscle development}

The quadriceps muscles of 20-week-old rats were weighed. As shown in Figure 4, the weights were greater in both administered groups than the control group, increasing by 18 and $31 \%$ in rats given AESL at doses of 150 and 300 $\mathrm{mg} / \mathrm{kg} /$ day, to $3.43 \pm 1.07$ and $3.80 \pm 0.95 \mathrm{~g}$ (control: $2.89 \pm 0.38 \mathrm{~g}$ ), respectively. The weight of quadriceps muscles was significantly increased in the group administered AESL 300 $\mathrm{mg} / \mathrm{kg}$ daily.

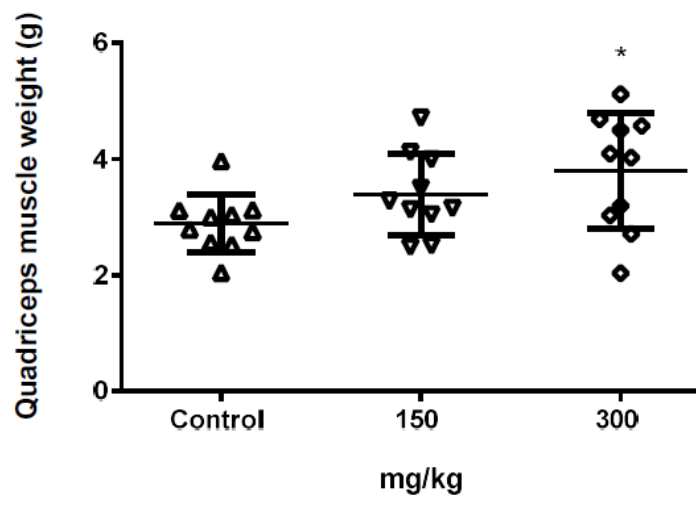

Figure 4: Effect of AESL on muscle mass. Hind limb quadriceps muscles were weighed after 4 weeks of AESL administration. Each dot is the mean weight of the left and right muscles. $p<0.05$ compared to control

\section{Sperm counts and motility}

As shown in Figure 5, the number of epididymal sperm increased by 6 and $24 \%$ in the group administered AESL 150 and $300 \mathrm{mg} / \mathrm{kg}$ daily, to $5.91 \pm 1.09 \times 10^{7}$ and $6.9 \pm 0.99 \times 10^{7}$ (control: $5.55 \pm 1.23 \times 10^{7}$ ), respectively. Aqueous extract of $\mathrm{SL}$ in the high-dose $(300 \mathrm{mg} / \mathrm{kg})$ has been found to statistically significant increase sperm count (Figure 5A). However, AESL did not significantly affect sperm motility (Figure 5B). Histological analysis shown that the control and administrated group testes were similar, with normal Leydig and Sertoli cells. The seminiferous tubules of administered rats were larger and denser than those of controls, and some tubules were clearly engaged in spermatogenesis. Dense spermatid nuclei and sperm heads within seminiferous epithelia were more obvious in the group administered with SL. Epididymal sperm masses were denser in the administered groups than the control group (Figure $5 \mathrm{C}$ ).

\section{DISCUSSION}

In this study, SL extract enhanced the levels of NO, NOS and cGMP in HUVEC and penile corpus cavernosum. These results corroborate those of Lee et al who proved that L. cuneata extract promotes phosphorylation of eNOS and Akt through NO-cGMP signaling in HUVEC and enhances vasodilation to relieve endothelial dysfunction [17].

\section{Blood steroid hormones were measured after}


A

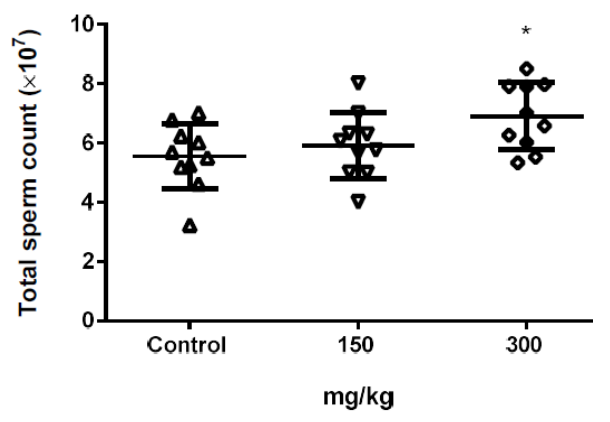

B

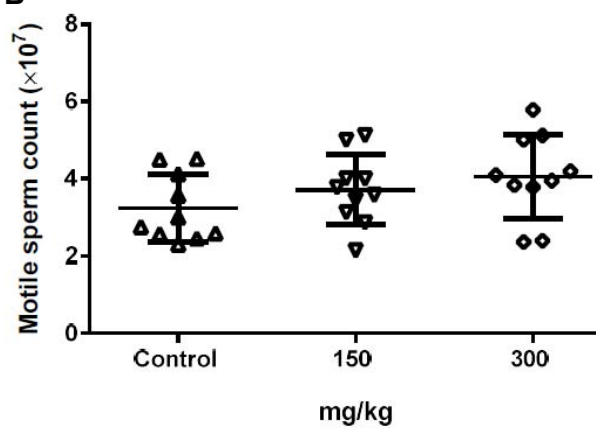

C control
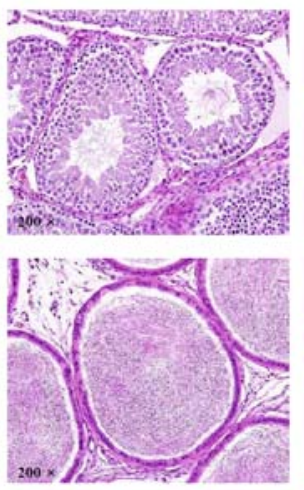

$300 \mathrm{mg} / \mathrm{kg}$

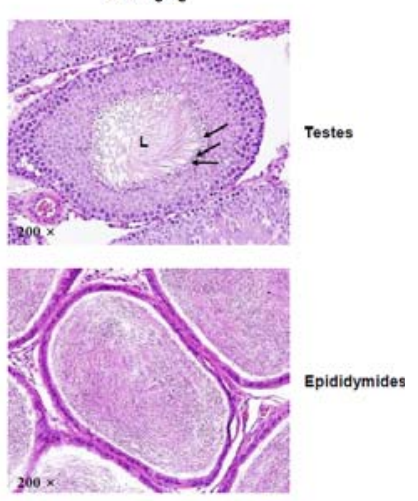

Figure 5: Effect of AESL on sperm numbers and spermatogenic tissue. Changes in $(A)$ total sperm and (B) motile sperm counts. (C) H\&E staining of the testis and epididymis of AESL-treated rats. In the top panel, the sperm heads (arrows) in the testis of AESL-treated rats are more elongated than those of the controls; the sperm tails are in the lumen (L). The bottom panel contains epididymal photomicrographs of control and AESL-treated rats; AESL slightly increased luminal sperm numbers. Magnification $\times 200$

administration of AESL for 4 weeks. The levels of DHT, 17ß-HSD, and testosterone were significantly elevated, while SHBG was significantly reduced, in the group given 300 $\mathrm{mg} / \mathrm{kg} /$ day AESL. The hormone-binding SHBG protein is produced by the liver. Approximately $40-60 \%$ of testosterone exists in inert state in the body in combination with SHBG, while only $1 \%$ of testosterone exists as free testosterone that is not bound to SHBG, indicating biological activity as a hormone [21]. Therefore, SHBG controls the in vivo action of testosterone [24]. Sex hormone-binding globulin increases and free testosterone decreases as human males age, triggering male menopause and metabolic disorders [25]. It was confirmed that increased blood testosterone by AESL administration was associated with decreased SHBG, which is consistent with data from Park et al [20]. The reduction in muscle mass during male menopause is accompanied by muscle weakness [26]. The weights of quadriceps muscle increased after 4 weeks of AESL administration; the difference between the highdose and control groups was significant. It may be that the increased testosterone enhanced muscle weight. Therefore, AESL may improve the reductions in testosterone and muscle mass associated with male menopause.

Testosterone secreted from Leydig cells in the testicles is known to have a significant effect on sperm development, sperm production and sperm motility by acting on the Sertoli cells that make up the seminiferous tubules in which sperm are formed [27]. In this study, male rats were given AESL for 4 weeks to increase their NO, NOS, cGMP, and testosterone levels, as well as sperm count and quadriceps muscle weight. Histology revealed that AESL, at both concentrations tested, did not damage the testis or epididymis. Aqueous extract of SL at 300 $\mathrm{mg} / \mathrm{kg} /$ day increased the number of sperms in the epididymal lumen. Aqueous extract of $\mathrm{SL}$ boosted testosterone levels (probably through valuable structural and functional effects on Leydig cells) associated with increased sperm production and motility.

\section{CONCLUSION}

The aqueous extract of SL improves sperm count and muscle mass by increasing the levels of NO, NOS, cGMP and testosterone in rats. Thus, SL extract can potentially be developed as an alternative therapeutic medicine for managing TDS.

\section{DECLARATIONS}

\section{Acknowledgement}

The present research was supported by Basic Science Research Program through the National Research Foundation of Korea (NRF) funded by the Ministry of Education (no. NRF2020R1A6A1A03043283), and by Leading Foreign Research Institute Recruitment Program through the National Research Foundation of 
Korea (NRF) funded by the Ministry of Science and ICT (MSIT) (no. NRF-2018K1A4A3A 02060572).

\section{Conflict of interest}

No conflict of interest is associated with this study.

\section{Contribution of authors}

We declare that this work has been carried out by the authors specified in this article and that all authors are responsible for all claims related to the content of this article. All the authors equally contributed to this study. SangJoon Mo, Eun Young Kim, Sun-Hyang Choi, and Jin Chul Ahn designed this study, carried out laboratory works, collected and analyzed the data, and also prepared the manuscript. Sanghyun Lee and Seong Lee also contributed to laboratory studies and analyzing the data.

\section{Open Access}

This is an Open Access article that uses a funding model which does not charge readers or their institutions for access and distributed under the terms of the Creative Commons Attribution License (http://creativecommons.org/licenses/by/ 4.0) and the Budapest Open Access Initiative (http://www.budapestopenaccessinitiative.org/rea d), which permit unrestricted use, distribution, and reproduction in any medium, provided the original work is properly credited.

\section{REFERENCES}

1. Kraemer WJ, Ratamess NA, Hymer WC, Nindl BC, Fragala MS. Growth hormone(s), testosterone, insulinlike growth factors, and cortisol: roles and integration for cellular development and growth with exercise. Front Endocrinol (Lausanne) 2020; 11: 33.

2. Araujo $A B$, Wittert GA. Endocrinology of the aging male. Best Pract Res Clin Endocrinol Metab 2011; 25(2): 303-319.

3. Feldman $H A$, Longcope $C$, Derby $C A$, Johannes $C B$, Araujo $A B$, Coviello AD, Bremner WJ, McKinlay JB. Age trends in the level of serum testosterone and other hormones in middle-aged men: longitudinal results from the Massachusetts male aging study. J Clin Endocrinol Metab 2002; 87(2):589-598.

4. Burnett AL. Nitric oxide in the penis-science and therapeutic implications from erectile dysfunction to priapism. J Sex Med 2006; 3(4): 578-582.

5. Jouannet $P$, Wang $C$, Eustach $F$, Kold-Jensen $T$, Auger $J$. Semen quality and male reproductive health: the controversy about human sperm concentration decline. APMIS 2001; 109(5): 333-344.

6. Bhasin S, Cunningham GR, Hayes FJ, Matsumoto AM, Snyder PJ, Swerdloff RS, Montori VM. Testosterone therapy in men with androgen deficiency syndromes: An Endocrine Society clinical practice guideline. J Clin Endocr Metab 2010; 95(6): 2536-2559.

7. Wang C, Nieschlag E, Swerdloff R, Behre HM, Hellstrom WJ, Gooren LJ, Kaufman JM, Legros JJ, Lunenfeld B, Morales $A$, et al. ISA, ISSAM, EAU, EAA and ASA recommendations: Investigation, treatment and monitoring of late-onset hypogonadism in males. Aging Male 2009; 12(1): 5-12.

8. Bivalacqua TJ, Champion HC, Mehta YS, Abdel-Mageed $A B$, Sikka SC, Ignarro LJ, Kadowitz PJ, Hellstrom WJ. Adenoviral gene transfer of endothelial nitric oxide synthase (eNOS) to the penis improves age-related erectile dysfunction in the rat. Int J Impot Res 2000; 12 : S8-S17.

9. Vanhoutte PM, Boulanger CM, Mombouli JV. Endothelium-derived relaxing factors and converting enzyme inhibition. Am J Cardiol 1995; 76(15): 3E-12E.

10. Nimmegeers S, Sips P, Buys E, Decaluwé K, Brouckaert $P$, Van de Voorde J. Role of the soluble guanylyl cyclase alpha1-subunit in mice corpus cavernosum smooth muscle relaxation. Int J Impot Res 2008; 20(3): 278-284.

11. Dashwood MR, Crump A, Shi-Wen X, Loesch A. Identification of neuronal nitric oxide synthase ( $\mathrm{nNOS}$ ) in human penis: a potential role of reduced neuronallyderived nitric oxide in erectile dysfunction. Curr Pharm Biotechnol 2011; 12(9): 1316-1321.

12. Davies KP. Development and therapeutic applications of nitric oxide releasing materials to treat erectile dysfunction. Future Sci OA 2015; 1(1): FSO53.

13. Shores MM, Matsumoto AM. Testosterone, aging and survival: biomarker or deficiency. Curr Opin Endocrinol Diabetes Obes 2014; 21(3): 209-216.

14. Gray A, Feldman HA, McKinlay JB, Longcope C. Age, disease, and changing sex hormone levels in middleaged men: Results of the Massachusetts male aging study. J Clin Endocr Metab 1991; 73(5):1016-1025.

15. Harman SM, Metter EJ, Tobin JD, Pearson J, Blackman $M R$. Longitudinal effects of aging on serum total and free testosterone levels in healthy men. Baltimore Longitudinal Study of Aging. J Clin Endocr Metab 2001; 86(2): 724-731.

16. Wu FCW, Tajar A, Pye SR, Silman AJ, Finn JD, O'Neill TW, Bartfai G, Casanueva F, Forti G, Giwercman A et al. Hypothalamic pituitary-testicular axis disruptions in older men are differentially linked to age and modifiable risk factors: The European male aging study. J Clin Endocr Metab 2008; 93(7): 2737-2745.

17. Lee JK, Kang DG, Lee HS. Vascular relaxation induced by aqueous extract of Lespedeza cuneata via the NOcGMP pathway. J Nat Med 2012; 66(1): 17-24.

18. Park SY, Kim HH. Effect of Lespedezea cuneata on the contraction of rabbit common carotid artery and corpus

Trop J Pharm Res, January 2021; 20(1): 127 
cavernosum. Korean J Orient Physiol Pathol 2013; 27(6): 809-817.

19. Rhee YH, Yoo SW, Lee S, Chung PS. Aqueous extract of Lespedeza cuneata improves male menopause by increase of nitric oxide and dihydrotestosterone. Food Sci Biotechnol 2018; 28(1): 253-260.

20. Park BK, Kim CW, Kwon JE, Negi M, Koo YT, Lee SH, Baek DH, Noh YH, Kang SC. Effects of Lespedeza Cuneata aqueous extract on testosterone-induced prostatic hyperplasia. Pharm Biol 2019; 57(1): 90-98.

21. National Institute of Health. Guide for Care and Use of Laboratory Animals. 1985, Publication No. 86-23, Bethesda, Maryland, USA

22. EC. Council Directive 86/609/EEC of 24 November 1986 on the approximation of laws, regulations and administrative provisions of the Member States regarding the protection of animals used for experimental and other scientific purposes (86/609/EEC) Official Journal L 358, Volume 29; 1986: 1-28; ISSN 0378-6978.
23. Walker WH. Non-classical actions of testosterone and spermatogenesis. Philos Trans $R$ Soc Lond B Biol Sci 2010; 365(1546): 1557-1569.

24. Raverot V, Lopez J, Grenot C, Pugeat M, Déchaud $H$. New approach for measurement of non-SHBG bound testosterone in human plasma. Anal Chim Acta 2010; 658(1): 87-90.

25. Swerdloff RS, Wang C. Andorgen and ageing male. Best Pract Res Clin Endocrino. Metab 2004; 18(3): 349-362.

26. Isidori $A M$, Giannetta $E$, Gianfrilli $D$, Greco $E A$, Bonifacio $V$, Aversa A, Isidori A, Fabbri A, Lenzi A. Effects of testosterone on sexual function in men: results of a meta-analysis. Clin Endocrinol (Oxf) 2005; 63(4): 381-394.

27. O'Donnell L, Stanton $P$, de Kretser DM. Endocrinology of the male reproductive system and spermatogenesis. In: Feingold KR, Anawalt B, Boyce A, Chrousos G, Dungan $K$, Grossman $A$, et al., editors. Endotext. South Dartmouth: MDText.com, Inc.; 2000 